\title{
PROBLEMS AND ISSUES IN USING COMPUTER-BASED SUPPORT TOOLS TO ENHANCE 'SOFT' SYSTEMS METHODOLOGIES
}

\author{
Mark Stansfield \\ Division of Computing and Information Systems \\ University of Paisley \\ High Street \\ Paisley PA1 2BE, Scotland \\ mark.stansfield@paisley.ac.uk
}

\begin{abstract}
This paper explores the issue of whether computer-based support tools can enhance the use of 'soft' systems methodologies as applied to real-world problem situations. Although work has been carried out by a number of researchers in applying computer-based technology to concepts and methodologies relating to 'soft' systems thinking such as Soft Systems Methodology (SSM), such attempts appear to be still in their infancy and have not been applied widely to real-world problem situations.

This paper will highlight some of the problems that may be encountered in attempting to develop computer-based support tools for 'soft' systems methodologies. Particular attention will be paid to an attempt by the author to develop a computer-based support tool for a particular 'soft' systems method of inquiry known as the Appreciative Inquiry Method that is based upon Vickers' notion of 'appreciation' (Vickers, 1965) and Checkland's SSM (Checkland, 1981). The final part of the paper will explore some of the lessons learnt from developing and applying the computer-based support tool to a real world problem situation, as well as considering the feasibility of developing computer-based support tools for 'soft' systems methodologies. This paper will put forward the point that a mixture of manual and computer-based tools should be employed to allow a methodology to be used in an unconstrained manner, but the benefits provided by computer-based technology should be utilised in supporting and enhancing the more mundane and structured tasks.
\end{abstract}

\section{INTRODUCTION}

As a result of the widespread application of CASE tools within structured information systems development there has been a growing interest over the last decade in developing computer-based support tools for 'soft' systems methodologies. Whilst computer-based support tools might provide obvious benefits for structured information systems development in terms of speed, efficiency and consistency, there are a number of questions and issues relating to the extent to which computer-based support tools might enhance the application of 'soft' systems methodologies.

One of the problems is that 'soft' systems thinking and structured/'hard' systems thinking are rooted in very different theoretical foundations which has a profound affect on how the concepts and ideas are applied through various methodologies and approaches. Whilst structured/'hard' systems methodologies are underpinned by precise rules and conventions and can be validated for consistency and correctness, 'soft' systems methodologies often lack precise rules and conventions, and thus, their application is guided more by the experiences of the user and the needs of the unique problem situation. This provides researchers with a number of obstacles and problems in attempting to develop computer-based support tools that remain faithful to the 'soft' concepts and ideas. In addition, once such tools have been developed, there is the issue of applying them within the context of real-world problem situations so that they can be assessed in determining the extent to which they actually enhance the 'soft' systems methodology that they are supposed to serve.

\section{COMPUTER-BASED SUPPORT TOOLS FOR 'SOFT'SYSTEMS METHODOLOGIES}

The application of computer technology in supporting the use of, or explaining the concepts relating to 'soft' systems thinking has been attempted by a number of authors and researchers over the last decade. Some examples of such work have included the development of software tools that aid the user in carrying out SSM, such as a computer-based support tool named 'Get Rich Quick!' (Avison et al., 1992) that provides graphical support to the user in the production and development of rich pictures. SSAMT (Davenport and Ayers-Hunt, 1995) is a windows based modelling tool that provides support mainly with aspects relating to selecting relevant systems, formulating root definitions and developing conceptual models within SSM. In addition, facilities for problem diagnostics as well as help screens for each of the stages of SSM are provided.

Zhang et al., (1997) developed a computer-based support tool known as the 'SoftCase toolkit' that provides a rich picture builder to the user through the use of drawing tools and pre-stored icons. Relevant systems can be named and associated with the rich picture as well as textual notes that can be included. In addition, the toolkit also provides the user support in the formulating root definitions and developing conceptual models as well as entering associations between the different stages of SSM. The full implementation of the toolkit also automatically generates a worksheet in comparing a conceptual model with the real-world, as well as automatically generating a Maltese Cross. Dunning-Lewis (1997) highlights a number of attempts at providing a computer-based support tool for the SSM user. These have included employing a DBMS package with OLE 
links to create a support tool for hold working documents of an SSM study, as well as a shell application that provides an interface to the user, that also makes use of a range of commercial software packages that may be utilised during a study.

Work has been carried out in developing computer-based support tools for teaching 'soft' systems concepts such as SSM using expert system technology (Stansfield, 1990; Stowell and Stansfield, 1991; Stowell et al., 1991). The computer-based support tool provided students with an overview of each of the seven stages comprising SSM, guidelines in the use of SSM as well as tutorial exercises, after which, the student can compare their answers with that of an expert's. This work was developed further using multimedia technology (Stowell et al., 1993) in which a more enhanced graphical user interface was utilised as well as incorporating audio expert advice into the computer-based support tool. To date, most of these software tools that have been developed to support the learning and application of SSM are still very much in the prototyping stage. In many instances the researchers have experienced difficulties in developing the computer-based support tools whilst remaining faithful to the theoretical and practical elements that underpin many 'soft' systems methodologies.

MENTOR (Daellenbach and Petty, 2000) is a multimedia, interactive educational package that was developed by Operational Research teachers as an alternative means for students to learn about systems thinking and Operational Research Methodology to be used conjunction with other learning methods such as lectures, tutorials and a text book. Use of the MENTOR multimedia computer aided learning package is considered to have helped staff cope with increased student numbers through decreasing tutorial preparation time and in providing continuity between topics (Simpson and Edwards, 2000).

\section{TECHNOLOGICAL INFLUENCES ON 'SOFT'SYSTEMS METHODOLOGIES}

The problems experienced by researchers in applying computer technology to 'soff' systems thinking appear to stem from a situation similar to that described by Winograd and Flores (1986. p96). In describing a number of tasks that a computer programmer carries out in developing a computer program, they highlight the situation in which "the programmer must have a clear analysis of just what constitutes the task and potential set of actions for the program". This highlights the point that in developing computer software, the programmer must be able to predict in advance as many of the possible scenarios and actions that will be performed by the user of the software. The use of technology may lead to a narrowing of the learning with regard to a problem situation in that it may be viewed in ways which best fit the representation provided by the technology, as opposed to providing new ways of addressing it. This point was discussed by Vickers (1983. p8) who warned about the dubious impact of technological systems by saying:

'It shapes its users' minds and habits; it limits as well as enlarges. 'To a man who has only a hammer, 'it has been said, 'everything tends to look like a nail.' A comprehensive survey of the computerized models now in use would surely show how closely concentrated they are on situations which lend themselves to such modelling".

The computer was regarded by Vickers (1987) as a tool of thought and as such shapes organisations and lives in the way that it is used, since it is not neutral. Thus, Vickers was warning against viewing and creating a world that merely mirrors and represents the present understanding of computer-based technology (Vickers, 1978).

In using computer technology as a vehicle for applying methodologies based on 'soft' systems thinking, the practitioner may be in a situation in which he/she is declaring how the methodology will be used before any learning and appreciation has taken place among the participants. This anticipation of outcomes appears to run contrary to the theoretical underpinning of 'soft' systems thinking in which the way a particular method is applied within a problem situation is determined by the learning cycle. 'Appreciative' experiences that are gained by the participants should not be dictated by a computer programmer or the limits of a particular technology. Thus, a danger with computer-based technology is that it might constrain the user in terms of how they might apply it to a problem situation (Dunning-Lewis, 1997). In addition, the increasing ease of use of computer technology with the use of interactive screens offering many different options may either make a user feel overpowered or overwhelmed in that the technology might distract them from the exploration of the problem situation (Dunning-Lewis, 1997). Equally as problematical might be the case in which the user is given the impression that through the technology they can easily grasp and understand the intricacies of a complex and challenging process of inquiry that underpins methodologies such as SSM (Kreher, 1993). This may be applicable especially in situations when a computer-based support tools provides advice about how a problem situation might be addressed since the thought processes and the creativity of the user might be constrained (Zhang et al., 1997). 


\section{THE DEVELOPMENT OF A COMPUTER-BASED SUPPORT TOOL TO ENHANCE A 'SOFT' SYSTEMS METHOD OF INQUIRY}

The 'soft' systems method of inquiry for which the computer-based support tool described in this section was developed to enhance was the Appreciative Inquiry Method. The Appreciative Inquiry Method (West, 1992; 1995) draws upon the work of Vickers (1965) and Checkland (1981) in providing the IS analyst and other participants within the problem situation with a means of exploring less structured, difficult-to-describe elements associated with knowledge elicitation and information systems provision.

Attempts by other authors and researchers at providing computer-based support tools for 'soft' systems methodologies such as SSM, led to research into investigating the extent to which the Appreciative Inquiry Method, that draws upon a number of concepts and ideas from SSM, might be enhanced by computer-based technology. The two software platforms that were considered by the author for the development of the computerbased support tool were multimedia authoring software and hypermedia authoring software. Such software platforms appeared to be more suited as an output medium in which information is represented through various media in the form of an interactive 'book' through which the end-user can browse information deemed relevant. A study into small business marketing was used as a means of learning about the Appreciative Inquiry Method and the computer-based support tool. Due to pressures which arise from a lack of resources such as a time, manpower and money, many small business managers and business practitioners do not adequately reflect and explore the notion of marketing, how it is carried out and its affect upon the business as a whole. Furthermore, there does not appear to be any clear method or process of inquiry that practitioners can adopt easily to allow them to carry out this process of exploration and reflection. Whilst the domain of small business marketing contains certain structured elements, the domain also relies on many experiential, subjective elements that are reliant upon the judgement of the practitioner. The study supported practitioners in their exploration and reflection of small business marketing as well as providing a real-world context within which to assess the computer-based support tool.

The manual-based version of the Appreciative Inquiry Method was used initially with the participants to allow lessons to be learnt that could be fed into the development of the computer-based support tool. Once developed, the computer-based support tool was then used with the participants so that the tool could be assessed as well as comparisons made with the manual-based method of inquiry. In using the computer-based support tool a portable notebook computer was used by the IS analyst which meant that the approach could be transported easily to the participants' place of work, thus causing the minimum of disnuption to their busy schedules. The participants in the study included small business owner-managers, small business advisors and consultants and business and marketing academics.

The Appreciative Inquiry Method can be broken down into three iterative phases:

\section{Phase I - systems maps}

Systems maps are used as a means of representing those important elements that a participant might consider relevant to a problem situation. A systems map is a pictorial representation that draws upon the conventions of a Venn diagram (T301, 1984). The participants are presented with a area of interest which is placed in the central element of the systems map. The area of interest is decided upon prior to the first session through discussions with the participants. This area of interest may be altered as a result of learning about the problem situation during the session. The participants are encouraged to explore a range of issues relating to this central element by adding a secondary layer of elements, and a tertiary layer linked to the secondary layer, if appropriate, and thus, building up the map. The elements comprising the map may be either separated or they may overlap each other to highlight some link or relationship depending on how the participant wishes to represent their view of the situation. The systems map also serves as a platform for discussion between the IS analyst and the participants, and as a means of clarifying points, as well as learning and reflecting about the situation.

With regard to the computer-based support tool, the systems map was created using a small control panel that enabled the participants to add map elements and move them around the screen as they wished. The users were able to edit and delete any of the elements on the map using the mouse or trackerball device. In comparison to the manual-based method of inquiry where large sheets of paper could be used, the size of the computer screen meant that the participants had little space to construct a systems map. This limitation was recognised and, consequently, two facilities were incorporated into the computer-based support tool in an attempt to minimise any possible adverse effects. The first of these was a scroll bar and zoom-in feature to allow the use of as much of the screen as possible, and the second, a small on-screen notepad facility allowed the participants to type in ideas whilst constructing the map. Since in using the map manually the participants would often annotate their maps and make notes beside their maps, the notepad facility in the computer-based support tool provided the participants with the opportunity of continue making notes if they so wished.

An example of a systems map produced using the computer-based support tools is shown in figure 1 . 


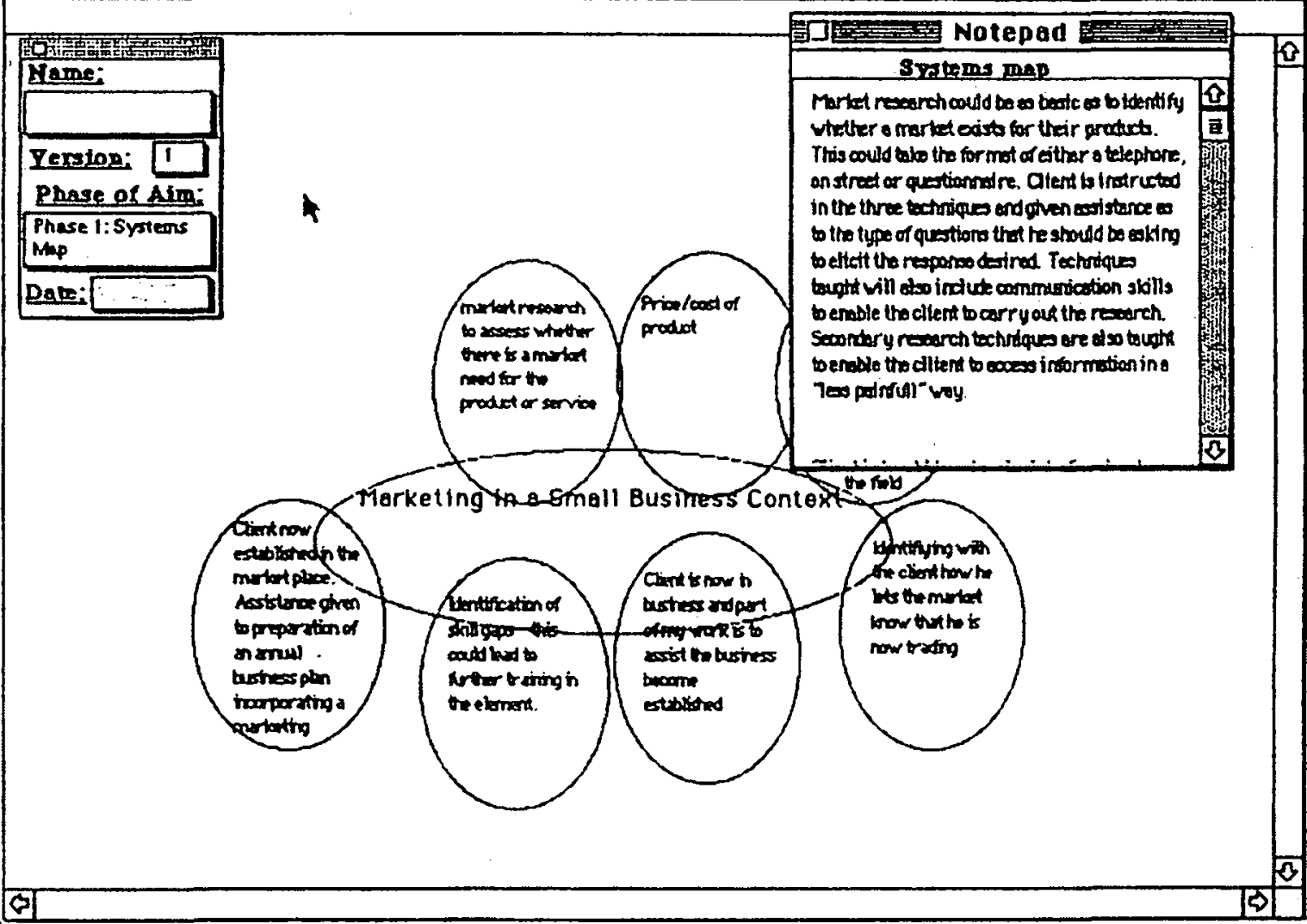

Figure 1: An example of a systems map produced using the computer-based support tool

\section{Phase II - CATWOE and root definition}

Systems map elements are translated into purposeful activities using the CATWOE elements of SSM. The elements are Customers, Actors, Transformation process, Weltanschauung, Owners and Environmental constraints. The elements are used to provide a careful description of the 'system' through the development of a root definition. The importance of using the CATWOE questions and formulating root definitions is that they provide a means of exploring the participants' Weltanschauung concerning the problem situation. This is made explicit in investigating the participants' understanding of the named activities as a whole, as opposed to it being fragmented and 'piecemeal'. An activity model, that is similar in format to a conceptual model, is developed from the root definition as a means of representing diagrammatically the activities and relationships that need to be in place for the overall purposeful activity as identified by the participants to take place.

In relation to the computer-based support tool, in providing the framework for asking questions relating to CATWOE, a conscious effort was made not to use systems terms that may have confused the participants. This was an important lesson learnt from using the manual-based method of inquiry, in that the questions posed to the participants used terminology that could be understood easily. By choosing a CATWOE element (e.g. 'Who has control over the named activity', the owner element of CATWOE), the participants were presented with a box in which to type in their response.

The framework for asking questions relating to CATWOE is shown in figure 2. 
Editor Reset Develop expert knouledge Save expert knowledge instructions

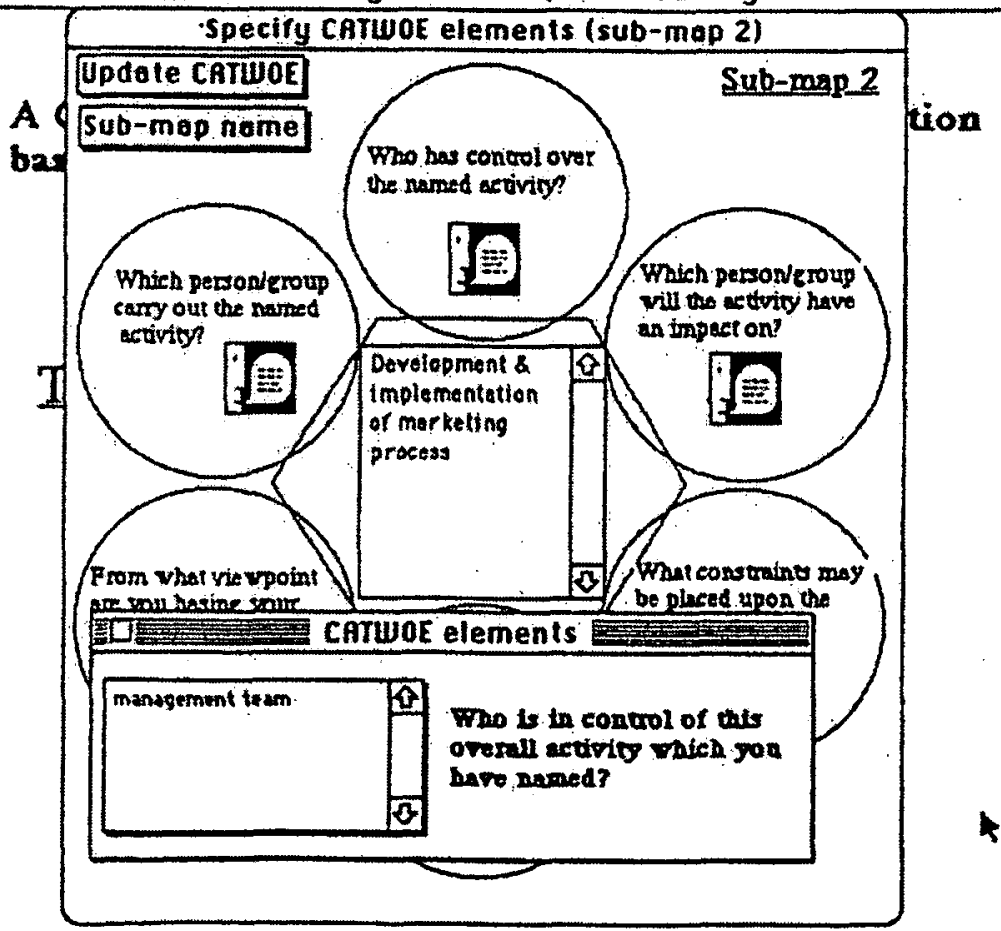

Figure 2: The framework for asking questions relating to CATWOE using the computer-based support tool

The answers to all of the CATWOE elements as provided by a participant where input using pre-defined nodes and links from the previous screen where the participant typed in their response to the CATWOE questions. The CATWOE answers, which were colour coded to highlight and represent the different CATWOE elements, could then be input into a pre-defined root definition. This allowed a workable root definition to be formulated quickly that could then be edited accordingly. This was considered by the IS analyst as possibly contributing to helping with the somewhat time consuming task of formulating root definitions. Any of the text in the root definition could be edited and the elements moved around the screen to provide a format to suit the IS analyst's needs. The colour coding of the different CATWOE elements also meant that the elements could be identified easily in the root definition. Furthermore, the CATWOE elements could be updated using pre-defined nodes and links to take into account any changes to the root definition.

\section{Phase III - modelling and agenda}

The purpose of the activity model is to provide a means of representing the activities and relationships that need to be in place for the overall purposeful activity, as identified by the participants, to take place. The activity model is used as a means of furthering the learning process with the participants in that the model may be developed further and used as an agenda for further exploring the problem situation.

In relation to the computer-based support tool, during the process of developing an activity model, both the root definition and the transformation process element of CATWOE could be viewed easily on the screen that could be referred to in assisting the development of an activity model. The activity model could be drawn using a control panel that allowed the IS analyst and the participants to create and name activities as well as connect them using arrows. Furthermore, the participants could be prompted to define criteria relating to the $3 \mathrm{E}$ 's, namely effectiveness, efficacy and efficiency as a check as to whether the transformation process had been identified successfully (Checkland and Scholes, 1990). The activities as shown in an activity model were then transferred to an agenda using pre-defined nodes and links. The agenda was used with the participants as a way of comparing the situation in the real-world, with model(s) developed during the sessions. This comparison formed the basis for further investigation and appreciation of the situation.

An example of an agenda developed from an activity model is shown in figure 3. 


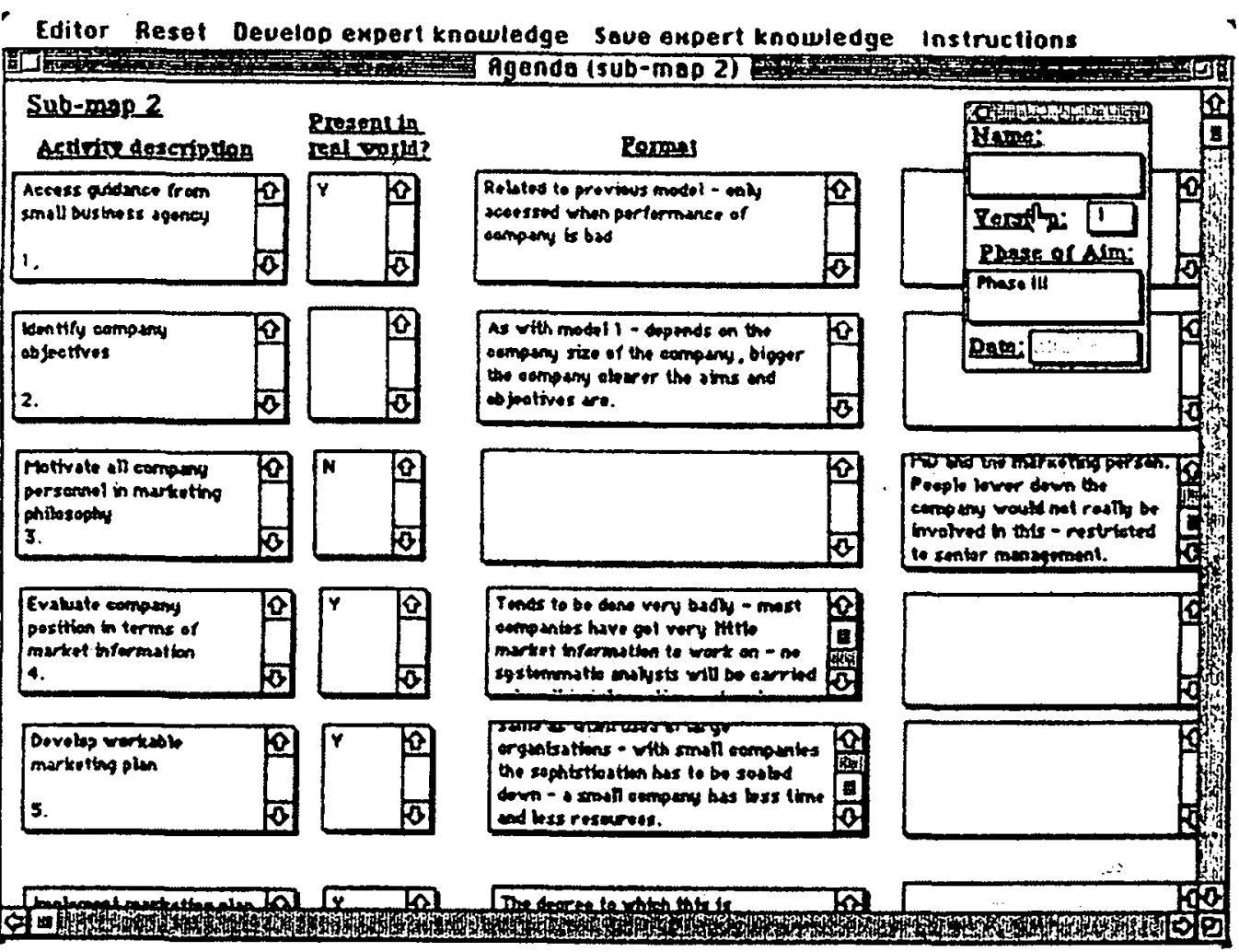

Figure 3: An example of an agenda developed from an activity model

A feature of the computer-based support tool was the provision of a computer-assisted learning facility with regard to the various techniques the participants may encounter. The use of the computer-assisted learning facility was used to support the IS analyst in introducing and explaining the techniques to the participants through the use of examples, graphical representations and simulations. Another feature provided by the computer-based support tool was a 'screen snap' facility that allowed 'snap shots' of the computer screen to be taken at any point in the discussion that could be stored for future reference with regard to the investigation. This also enabled the contents of the screen to be printed out so that the participants could receive a paper copy of the techniques that allowed them to reflect on any issues after the session.

\section{LESSONS FROM APPLYTNG THE COMPUTER-BASED SUPPORT TOOL TO A REAL-WORLD PROBLEM SITUATION}

There were a number of important lessons that were learnt by the author in relation to the role of the computerbased support tool as applied to the small business marketing study. Some of the lessons are outlined in this section, however, a more detailed discussion and analysis of the lessons can be found in Stansfield (1997). The computer-based support tool did provide some improvements, the most notable of which was:

\section{Editing}

The majority of the participants considered the ability to easily edit their systems maps, root definitions and activity models encouraged them to refine their initial responses and thoughts regarding the problem situation, since they did not have to redraw a whole model or map. The ability to edit a model or map on the computer screen enabled them to interact with the techniques and the IS analyst much more freely since they could try out ideas and explore thought processes. This contrasted with using the manual method of inquiry in which the maps and models would often become messy and difficult to read and follow as a result of numerous edits during a session. Furthermore, it was time consuming and mundane having to manually redraw maps and models that often interrupted the flow of the session.

In addition, the speed and ease of access to previous material that the computer-based support tool provided meant that material from previous sessions could be easily displayed on-screen. This was particularly useful when a number of weeks had elapsed between sessions and the participants wanted to refresh their memories as 
to what had taken place in previous sessions. This contrasted with the manual-based method of inquiry in which the IS analyst would often have to carry numerous documents and folders containing paper versions of maps, root definitions and models as well as notes from previous sessions which was cumbersome and took up a lot of space.

However, there were a number of substantive problems with the computer-based support tool that included:

\section{Flexibility}

The issue of flexibility was compounded by the need to predict in advance what a participant may require from the software in exploring their area of interest. Because of the flexibility provided by the manual-based method of inquiry, the computer-based support tool proved inflexible due to the difficulty of anticipating all of the possible scenarios in which a participant may wish to use the approach. In more traditional, 'conventional' IS analysis the use of more structured methods and approaches is usually clearly defined by specific syntax and notations, and hence, is more open to such predictions in developing computer software to operationalise them. Apart from a limited number of simple guidelines, there are few formalised rules associated with 'soft' systems methodologies such as SSM and the Appreciative Inquiry Method. The idea is that participant should be allowed to explore and express their views and ideas with the minimum of pre-defined constraints.

When using the computer-based support tool there is a danger that if a participant wishes to perform a task that has not been predicted, then they have to alter their thinking to fit the particular format provided by the computer software. Such a situation could be argued to interfere, and consequently limit a participant's learning experience and thus, undermine the underlying intention of 'soft' systems thinking. There is a danger that a participant's views and thinking may be misrepresented because of the problems created by the computer-based support tool. During the study, on several occasions, participants when using the computer-based support tool were unable to adapt a technique or use it in a particular way that suited their way of thinking because it had not been accounted for in the development of the computer software. When using the manual-based method of inquiry the participants could easily adapt techniques or bring in new ones that they considered appropriate to the situation.

\section{Ease of Use}

Notwithstanding advances in the ease of use of computers, the computer-based support tool was not as easy to use as the manual-based method of inquiry. The manual approach could be learnt after a very short introduction and its flexibility allowed the participants to adapt it to suit their particular way of thinking. That was not the case when they used the computer-based support tool. For example, the participants had to use a keyboard, a mouse and some edit commands before they could begin to think about the problem situation being explored. This highlights the problem of making the user interface as natural and transparent as possible so that carrying out tasks using the computer-based support tool is at least no more complicated than carrying out the task manually.

When using the manual-based method of inquiry, the participants did not require instructions about the mechanics of drawing and writing. Although familiarisation with the computer or more advanced technology may reduce these problems, the very nature of the tasks seemed to act as a distraction to the main activity that did not exist in the manual-based method of inquiry. Some of the participants had reservations about using the computer technology because of a claimed lack of computer literacy, physical disabilities and a reluctance to spend the time to learn to use it. Participants have to be convinced that using a computer-based support tool will save them time and effort and are not just using computer-based technology for its own sake.

\section{ISSUES RELATING TO THE EXTENT TO WHICH COMPUTER-BASED SUPPORT TOOLS CAN ENHANCE ‘SOFT' SYSTEMS METHODOLOGIES}

There were a number of generic issues about the use of computer-based support tools for 'soft' systems methodologies that appear to transcend the choice of specific software and hardware. Whilst the utilisation of more sophisticated software may have overcome some of the problems encountered by the author, there are a number of issues that could be attributed to computer technology generally, which need to be addressed in the future.

To become familiar with computer technology the user has to invest a certain amount of time and effort in learning to use it. However, when this issue is related to the real-world problem situations, problems may arise in that certain participants may not be able to spare the extra time, effort and money required to familiarise themselves with the technology before the session can proceed. In addition, the time, effort and costs involved in becoming familiar with technology have to be assessed against the possible benefits that such technology can bring to the user. If the advantages of using computer-based technology are only marginal, then it might not be feasible to use a computer-based support tool as opposed to the manual-based method of inquiry. A point related 
to the issue of familiarity with computer technology is the regularity with which the user may wish to perform a task. For example, if a user participates very occasionally in a 'soft' systems study or as a 'one-off' event, then the time spent in familiarising themselves with computer software may not be justified. They could use a manual-based method of inquiry without the need for spending extra time, effort and expense on training in certain computer-based technology.

When a user is trained to carry out tasks using computer-based technology, there may be a danger that the user is led to believe that the task can only be performed in a certain way or that they have to follow particular conventions provided by the computer software. This may have an effect of constraining a user's thinking or misleading them about the task being performed. Thus, computer-based technology may impose or reinforce rational and logical thinking about a problem or task when it may not necessarily be the case. Thus, it is important that computer-based technology does not constrain the users' creativity in carrying out a task or thinking about a problem. Therefore, any computer technology should be flexible enough to allow the user to be creative with regard to thinking about the problem situation.

The user of the computer support tool should not be overburdened or overwhelmed by the extra responsibilities they may face in learning to use and apply the computer-based technology. Some people may dislike using computer-based technology and it may cause them undue distress and pressure during the session, which may distract or inhibit them in exploring their problem situation. Therefore, it is important that a computer-based support tool does not detract from any participative debate that may be required when thinking about a problem situation as a result of users becoming too focused on the intricacies of using the software.

\section{CONCLUSION}

It is unlikely that computer-based support tools could fully automate the process of inquiry that underpins 'soft' systems thinking. Many 'soft' systems methodologies such as SSM and the Appreciative Inquiry Method provide few formal rules that dictate their use. Participants can adapt and customise the approaches to suit the needs of a problem situation in a manner that would be largely unacceptable when using more 'hard'/structured systems methodologies and approaches. A more likely and feasible scenario is that a mixture of manual and computerbased tools could be employed during the course of a study. A manual-based method of inquiry could be used for the more creative aspects of the study in actually investigating the problem situation. This would allow a methodology to be used in an unconstrained manner so that tools and techniques can be adapted to suit the thinking of the participants, as well as being able to apply the methodology in a non-sequential manner. The main benefit that a computer-based support tool may provide in enhancing a 'soft' systems methodology is more at an administrative level in terms of allowing material to be stored and accessed more easily as well as in allowing material to be edited more freely during a session. Thus, computer-based technology could support and enhance the more mundane and structured tasks associated with a 'soff' systems methodology. It is the author's view that the thinking should be left to the people involved in the problem situation who should be allowed to explore a problem situation unhindered by any constraints imposed by computer-based technology.

The work presented in this paper presents some initial lessons from developing and applying a computer-based support tool to a real-world problem situation. Much more work needs to be carried out in applying such computer-based support tools within the context of real-world problem situations before they can be assessed in terms of the extent to which they enhance the ideas and concepts that underpin them.

\section{REFERENCES}

Avison, D.E., Golder, P.A. \& Shah, H.U. (1992) "Towards an SSM Toolkit: Rich Picture Diagramming", European Journal of Information Systems, Vol 1. No 6, pp397-407.

Checkland, P.B. (1981) Systems Thinking, Systems Practice, Wiley, Chichester.

Checkland, P.B. \& Scholes, J. (1990) Soft Systems Methodology in Action, Wiley, Chichester.

Daellenbach, H. \& Petty, N.W. (2000) "Using MENTOR to Teach Systems Thinking and OR Methodology to First-Year Students in New Zealand", Journal of the Operational Research Society, Vol 51, pp 1359-1366.

Davenport, M.S. \& Ayers-Hunt, J. (1995) "Soft Systems Analysis and the Modelling Tool (SSAMT): Computerbased Support for Conducting Soft Systems Thinking", Critical Issues in Systems Theory and Practice (Eds.: K. Ellis, A. Gregory, B. Mears-Young, G Ragsdell), Plenum Press, New York, pp291-295.

Dunning-Lewis, P.J. (1997) "Concerning Computer-Based Support Tools for the User of Soft Systems Methodology", Systems for Sustainability, (Eds.: F.A. Stowell, R.L. Ison, R. Armson, J. Holloway, S. Jackson, S. McRobb), Plenum Press, New York, pp459-463

Kreher, H. (1993) "Critique of Two Contributions to Soft Systems Methodology", European Journal of Information Systems, Vol 2, No 4, pp304-308.

Stansfield, M.H. (1990) The Development of an Expert System to Aid the User of Soft Systems Methodology. M.Sc. Project, School of Information Science, Portsmouth Polytechnic (Unpublished). 
Stansfield, M.H. (1997) The Effect of Computer-based Technology in Attempting to Enhance a Subjective Method of Knowledge Elicitation, Ph.D. Dissertation, University of Paisley (unpublished).

Simpson, G. \& Edwards, J.S. (2000) "Was it Good for Them? Reflections on the Use of MENTOR and Changes in Course Design Using General Performance Measures", Journal of the Operational Research Society, Vol 51, pp1352-1358.

Stowell, F.A. \& Stansfield, M.H. (1991) “A First Step Towards the Automation of SSM?”, Systems Thinking in Europe, (Eds.: M.C. Jackson, G.J. Mansell, R.L. Flood, R.B. Blackham and S.V.E. Probert), Plenum Press, New York, pp319-325.

Stowell, F.A., West, D. \& Stansfield, M.H. (1991) "The Application of an Expert System Shell to an Unstructured Domain of Expertise: Using Expert System Technology to Teach SSM", European Journal of Information Systems, Vol 1, No 4, pp281-290.

Stowell, F.A., West, D. \& Javelaud, V. (1993) "Developments in the Automation of SSM: Tutorials Using Multimedia Technology", Systems Science: Addressing Global Issues (Eds.: F.A Stowell, D. West, J.G Howell), Plenum Press, New York, pp269-274.

T301 (1984) Complexity, Management and Change: Applying a Systems Approach. Block 1 Introduction, 1984, The Open University, Milton Keynes.

Vickers, G. (1965) The Art of Judgement: A Study of Policy Making, Chapman and Hall, London

Vickers, G. (1978) Presidential Address, 22nd North American Annual Meeting of the International Society for General Systems Research, Washington D.C.

Vickers, G. (1983) Human Systems are Different, Harper and Row, London.

Vickers, G. (1987) Policymaking, Communication and Social Learning. (Eds.: G.B. Adams, J. Forester and B.L. Cantron), Transaction, Inc, New Jersey.

West, D. (1992) 'Knowledge Elicitation as an Inquiring System: Towards a 'Subjective' Knowledge Elicitation Methodology", Journal of Information Systems, Vol 2, pp31-44.

West, D. (1995) "The Appreciative Inquiry Method: A Systemic Approach to Information Systems Requirements Analysis", Information Systems Provision: The Contribution of Soft Systems Methodology, (Ed.: F.A Stowell), McGraw-Hill Book Company, London, pp 140-158.

Winograd, T. \& Flores, F. (1986) Understanding Computers and Cognition: A New Foundation for Design, Ablex Publishing Corporation, Norwood, New Jersey

Zhang, J., Smith, R. \& Watson, R.B. (1997) "Towards Computer Support of the Soft Systems Methodology: An Evaluation of the Functionality and Usability of an SSM Toolkit", European Journal of Information Systems, Vol 6, pp129-139. 